\title{
Transient Erythroblastopenia of Childhood
}

National Cancer Institute

\section{Source}

National Cancer Institute. Transient Erythroblastopenia of Childhood. NCI Thesaurus.

Code C131683.

An acquired pure red cell aplasia that is self-limited. It is the most common cause of decreased red blood cell production in the pediatric population, and typically presents as a normocytic anemia with reticulocytopenia in an otherwise asymptomatic and normal child with no evidence of other causes for anemia, including blood loss, hemolysis, nutritional deficiency, or malignancy. 